\title{
Isolated interrupted inferior vena cava with azygos continuation mimicking paraesophageal lymph node enlargement
}

\author{
U. Yılmaz ${ }^{1}$, H. Halilcolar¹, I. Unsal1, S. Yapıcıoglu1, \\ Y. Yıldırım¹, M. Apaydın²
}

ABSTRACT: Isolated interrupted inferior vena cava with azygos continuation mimicking paraesophageal lymph node enlargement. U. Yılmaz, H. Halilcolar, I. Unsal, S. Yapıcıoglu, Y. Yildırım, M. Apaydin.

We report a case of interrupted inferior vena cava with azygos continuation diagnosed as a isolated finding in a patient with lung carcinoma. Findings of the unopacified CT scan initially simulated a paraesophageal lymphadenopathy. The contrast - enhanced spiral CT scan showed a dilated azygos vein in the absence of definable inferior vena cava.

Monaldi Arch Chest Dis 2006; 65: 4, 228-230.

Keywords: Azygos vein, vascular anomaly, mimicking lymph node.

${ }^{1}$ Division of Pulmonary Medicine, Suat Seren Chest Disease and Surgery Training and Research Hospital, Izmir,

1 Division of Radiology, Suat Seren Chest Disease and Surgery Training and Research Hospital, Izmir, Turkey.

Correspondence: Ufuk Yllmaz; Mustafa bey caddesi No 41/10 Alsancak 35220,Izmir,Turkey; e-mail: drufukyilmaz@e-kolay.net

Azygos vein dilation has been described in patients with portal vein hypertension, obstruction of superior or inferior vena cava, right heart failure and interruption of the inferior vena cava (IVC). Interrupted IVC with azygos continuation is a rare clinical condition but in this situation, the azygos system dilates to accommodate visceral and lower the extremity of blood return to the right atrium. Although uncommon, these anomalies have been described as an isolated finding and can mimic a mediastinal mass $[1,2,3,4]$. If isolated interrupted IVC with azygos continuation is together with lung carcinoma, it can be misinterpreted as a lymphadenopathy in a patient who has been evaluated with unopacified CT scans.

We present a case of isolated azygos continuation of the interrupted IVC mimicking a paraesophageal lymph node enlargement in a patient with a left hilar mass.

\section{Case report}

A 68-year-old man was admitted to our hospital presenting a left tumour mass and lymphadenopathy on unopacified Computed Tomography scan of the chest and metastasis of the first and fourth lumbal vertebrae on Magnetic Resonance Imaging. The physical examination revealed a non-healthy man. He was febrile $\left(37.5^{\circ} \mathrm{C}\right)$ and had a blood pressure of $150 / 100 \mathrm{mmHg}$, a heart rate of 100 beats $/ \mathrm{min}$. Breath sounds were diminished on both lungs. The heart and abdominal ex- aminations were unremarkable. The neurological examination was significant for paralysis in both lower extremities. A posteroanterior chest x-ray revealed a left hilar mass. Contrast-enhanced spiral CT scan of the chest showed a tumour mass at the superior segment of the lower left lobe with invasion of the descending aorta and dilated azygos vein (figure 1), mild enlargement of the arch of the azygos, and enlargement of the retrocrural portions of these same veins in the absence of definable inferior vena cava (figure 2). Coronal (figure 3 ) and sagittal reconstructions showed that the azygos vein was as large as the descending aorta.

Fiberoptic bronchoscopy showed no endobronchial lesion except of narrowing and mucosal hyperemia of the superior segment of the lower left lobe. The cytopathologic examination of the brushing and washing specimens was benign.

In a routine ultrasound examination of the abdomen, the stomach, heart, liver and spleen were normally positioned and the gallbladder was present. A detailed ultrasound examination of the IVC was not carried out owing to the patient's poor health.

Diagnosis of our patient was accepted to be lung carcinoma with bone metastasis and palliative radiotherapy planned. However, our patient did not accept the treatment and was discharged.

\section{Discussion}

The azygos vein usually originates below the diaphragma at the level of the first two lumbal ver- 


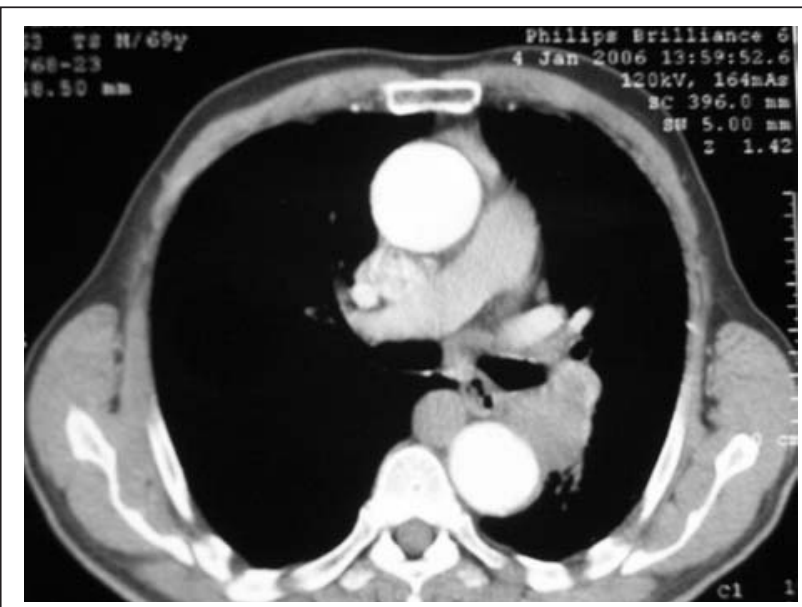

Fig. 1. - CT section revealed left hilar mass and round opacity (dilated azygos vein) lying adjacent to the wall of the oesophagus.

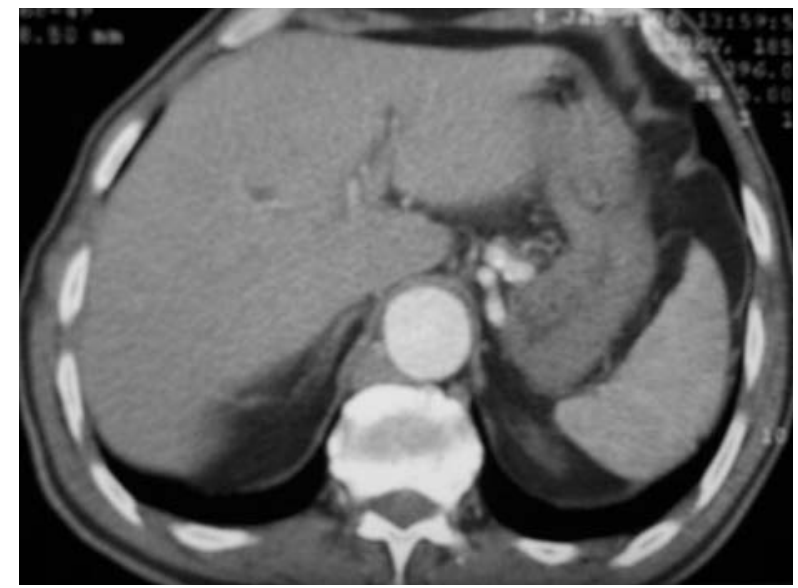

Fig. 2. - CT section at the level of upper abdomen revealed enlargement of the retrocrural portions of azygos vein in the absence of definable inferior vena cava.

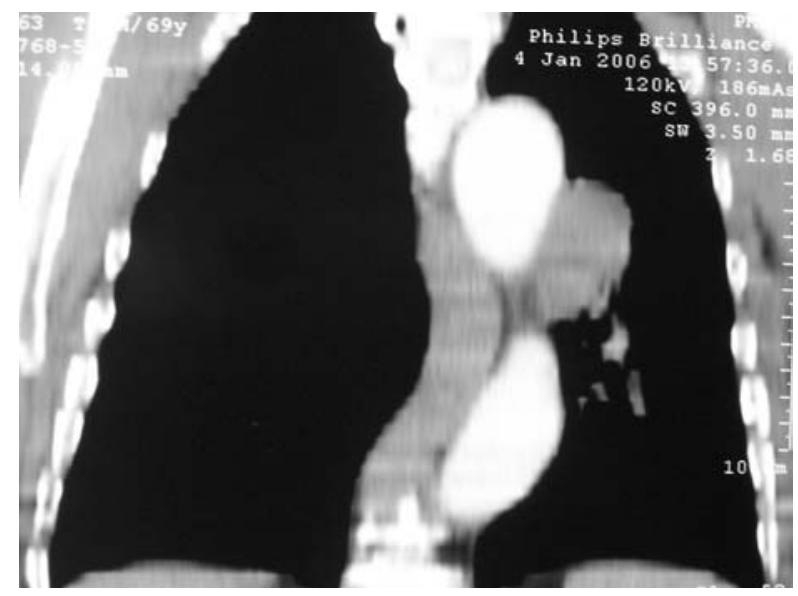

Fig. 3. - Reconstructive coronal CT view, dilated azygos vein continuing on the right side of the aorta and mass lesion on the left side of the aorta.

tebrae by a union of the ascending lumbal vein and the right subcostal vein. It may also be joined at times by a tributary from the right renal vein, or a tributary from IVC. Generally, the azygos vein ascends in the posterior mediastinum on the right anterior aspect of the vertebral bodies. It arches for- ward over the right mainstem bronchus to drain into the superior vena cava at the level of fourth thoracic vertebrae.

Interrupted IVC with azygos continuation is a rare congenital anomaly that results from a connection failure between the right subcardinal vein and right vitelline vein [5]. This malformation is considered to be excellent marker for the presence of visceral heterotaxy and polysplenia syndrome [6]. Van Praagh et al. [7] reported an interrupted IVC in 39 of 46 (85\%) postmortem cases of visceral heterotaxy with polysplenia. But, isolated interrupted IVC with azygos continuation has been rarely described [8-10], comparable with the case we report.

Surgical resection has been the mainstay of curative treatment in lung carcinoma. The presence or absence of tumour cells in the mediastinal lymph nodes of these patients is a critical factor in determining their prognosis and treatment plans. CT scan is well entrenched as a tool in the armamentarium in the pre-operative stages of lung cancer. Unfortunately, the size of mediastinal lymph nodes does not always correlate with their tumour involvement [11]. Mediastinoscopy, mediastinotomy, Endo-esophageal ultrasound fine needle aspiration (EUS-FNA) and video-assited thoracoscopic surgery (VATS) remain a definitive means by which tissue is obtained. EUSFNA and VATS is an alternative method of assessing level 5 and 6 as well as the paraesophageal (level 8) and pulmonary ligament (level 9) nodes [12].

Azygos continuation may present in otherwise normal cases, but may also present in patients with lung carcinoma, comparable with the case we report. In this setting, dilated azygos vein that is identified along the paravertebral pleural reflection may be misinterpreted as a posterior mediastinal mass, a retrocrural mass or adenopathy. This might be a potential pitfall in the planning of the mediastinal nodal staging with invasive tests like VATS. Enlargement of the retrocrural portion of the azygos vein differentiates from lymphadenopathy in that continuous tubular structures are seen on contiguous slices and the marked enhacement after injection of contrast material [10]. In our case, the diagnosis of azygos continuation was initially misinterpreted as a paraesophageal lymphadenopathy because of the unopacifed CT scan.

In daily practice, when administering contrast material, scans of the mediastinum were performed predominantly during the arteriel phase like in our case. This might be a second potential pitfall in the diagnosis of an azygos continuation. This problem may be resolved by late contrast-enhanced scan on CT examination or by use of magnetic resonance imaging [9].

In conclusion, all physicians interested in the thoracic oncology should be aware of the interrupted IVC with azygos continuation. This finding can present in patients with lung carcinoma and can be mistaken for a mediastinal lymph node enlargement. 


\section{References}

1. Mihmanli I, Bulakbasi N, Kantarci F, Adaletli I, Pabus$\mathrm{cu}$ Y. The value of ultrasonography in interrupted inferior vena cava with azygos continuation. Eur J Ultras 2001; 14: 179-82.

2. Fernandes R, Israel RH. Isolated azygos continuation of the inferior vena cava in the elderly. Respiration 2000; 67: 229-33.

3. Podbielski FJ, Sam II AD, Halldorsson AO, et al. Giant azygox vein varix. Ann Thorac Surg 1997; 63: 1167-9.

4. Lee SY, Kuo HT, Peng MJ, Lin FJ, et al. Azygos vein varix mimicking posterior mediastinal massin a patient with a liver cirrhosis. A case report. Chest 2005; 127; 661-4.

5. Sadler TW. Cardiovascular system. In Langman's Medical Embryology, 6th edt. Williams \&Wilkins, Baltimore, 1990: 217-20.

6. Sheley RC, Nyberg DA, Kapur R. Azygos continuation of the interrupted inferior vena cava: A clue to prenatal diagnosis of the cardiosplenic syndromes. J Ultrasound Med 1995; 14: 381-7.

7. Van Praagh S, Santini F, Sanders SP, Cardiac malpositions with special emphasis on visceral heterotaxy (as- plenia and polysplenia syndromes). In: Fyler DC, (ed.) Nadas' pediatric Cardiology. Hanley and Belfus, Philadelphia, 1992: 589-608

8. Ramsaren EK, Filliberti AW, Spodick DH. Isolated anomalous inferior vena cava with azygos drainage. Cardiology 1995; 86: 257-8.

9. Celentano C, Malinger G, Rotmensch S, Gerbont S, et al. Prenatal diagnosis of interrupted inferior vena cava as an isolated finding: a benign vascular malformation. Ultrasound Obstrt Gynecol 1999; 14: 215-8.

10. Poll LW, Koch JA, Finken S, Lurz K, et al. Azygos continuation syndrome with aneurysm of azygos vein: CT and MR appearances. J Comput Assist Tomogr 1999; 23 (1): 19-22.

11. McKenna RJ, Lipshitz HI, Mountain CE, McMurtrey MU. Roentgenographic evaluation of mediastinal nodes for pre-operative assessment in lung cancer. Chest 1985; 88: 206-10.

12. Landreneau RJ, Hazelrigg SR, Mack MJ, et al. Thoracoscopic mediastinal lymph node sampling: usufel for mediastinal lymph node stations inaccessible by cervical mediastinoscopy. J Thorac Cardiovasc Surg 1993; 106: 554-8.

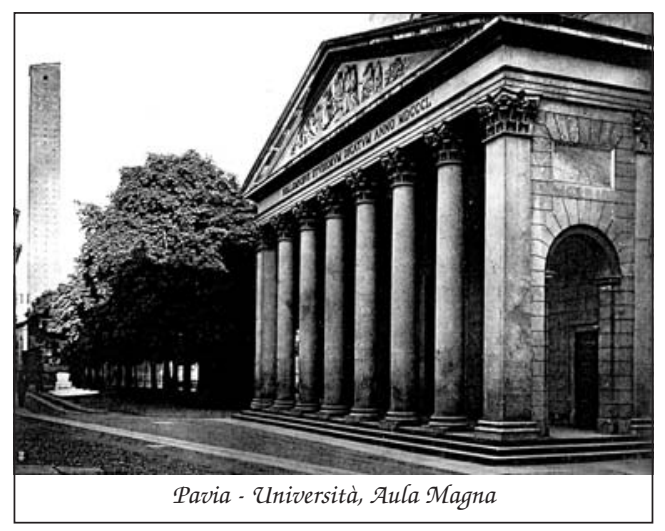

